\title{
Cardiac Tamponade and Splenic Littoral Cell Angioma: An Unusual Presentation of a Very Rare Disease
}

\author{
Rossi $S^{1}$, Pepe $\mathrm{R}^{1}$, Di Santo $\mathrm{M}^{1}$, Mucilli $\mathrm{F}^{2}$ and Schiavone $\mathrm{C}^{*_{1}}$ \\ ${ }^{1}$ Diagnostic Ultrasound Unit, "S.S. Annunziata Hospital”, “G. D’Annunzio University”, Italy \\ ${ }^{2}$ Thoracic Surgery Unit, "S.S. Annunziata Hospital”, “G. D’Annunzio University”, Italy
}

${ }^{*}$ Corresponding author: Schiavone C, MD, PhD, Professor, Unit of Diagnostic Ultrasound, Departement of Medecine and Science of Aging, "G. D'Annunzio University", Via dei Vestini 29, 66013 Chieti Scalo (CH), Italy, Fax: +39-0871-358969, Tel: +39-0871-358576, E-mail: cschiavone@unich.it

Citation: Rossi S, Pepe R, Di Santo M, Mucilli F, Schiavone C (2016) Cardiac Tamponade and Splenic Littoral Cell Angioma: An Unusual Presentation of a Very Rare Disease. J Case Rep Stud 4(3): 305. doi: 10.15744/23489820.4.305

Received Date: March 29, 2016 Accepted Date: June 18, 2016 Published Date: June 21, 2016

\begin{abstract}
Littoral cell angioma (LCA) is a rare benign vascular splenic tumor that can evolve, potentially, into a malignant form. It can be found incidentally in the majority of cases during ultrasound (US) or other imaging exams, performed for other problems. It has not a (US) or computed tomography (CT) pathognomonic pattern so diagnosis is made by histological and immunochemical analysis. This is a case of LCA discovered incidentally in an 81-year-old woman admitted to our hospital for dyspnea due to cardiac tamponade. The splenic disease was discovered during an US abdomen study performed to reveal a source of infection. Our patient was evaluated also with CT study that confirmed the presence of splenic lesions but could not make a diagnosis. The patient underwent a splenectomy that showed histological and immunochemical evaluations consistent with presence of LCA.
\end{abstract}

Keywords: Littoral cell angioma; Splenectomy; Vascular tumor

\section{Case Description}

An 81 old woman was admitted to our general medicine unit for dyspnea with obligatory orthostatic position due to heart failure. At physical examination the patient presented the Back's triad: jugular turgor, hypotension and reduced heart sounds, these are signs suggestive of cardiac tamponade. So she performed a chest X-Ray and echocardiogram that showed pleural effusion and the presence of conspicuous pericardial fluid afterwards treated with pericardiocentesis.

Laboratory tests revealed the presence of normal red blood cells count $\left(4.66 \times 10^{\wedge} 6 / \mathrm{ul}\right)$ with normal hemoglobin (13.6 g/dl), normal renal (creatinine $0.5 \mathrm{mg} / \mathrm{dL}$ ) and hepatic function (GOT25 U/L, GPT $36 \mathrm{U} / \mathrm{L}$, Total Bilirubin $0.4 \mathrm{mg} / \mathrm{dL}, \mathrm{INR} 1.1$ ), Quantiferon TB Gold negative, slight thrombocytopenia $\left(121.000 \times 10^{\wedge} 3 / \mathrm{mmc}\right)$ and slight augmentation of PCR value $(2.05 \mathrm{mg} / \mathrm{dL})$.

The analysis of the pericardial and pleural fluid found the presence of sterile exudates.

At this point, looking for the presence of local infection, an abdomen ultrasound study was performed and demonstrated multiple splenic hyperechoic focal lesions suspicious for malignancy, septic emboli, hemangiomatosis or amyloidosis (Figure 1, 2, 3 and 4); the CT abdomen study confirmed the presence of multiple focal lesions (Figure 5,6) that, in this technique, appeared hypodense and revealed the presence of a gastrointestinal stromal tumor (GIST) localized on the small gastric curvature that surgeons removed during spleen surgery.

In light of this exams, of the elevated value of PCR $(8.59 \mathrm{mg} / \mathrm{dL})$ and negativity of tumor (CEA, CA 19-9, CA 15-3, CA-125, NSE) and autoimmune markers (ANA, ENA, rheumatoid factor, anticitrullina antibodies) a lymphoproliferative disease was suspected, and a splenectomy was recommended.

Macroscopic analysis demonstrated the presence of splenomegaly $(11.5 \times 9.7 \times 7 \mathrm{~cm}$ in size and 257 gr. in weight) with a nodular surface that involved all splenic parenchyma; while, microscopic analysis, revealed the presence of vascular channels anastomosis alike splenic sinusoids with irregular lumen for the presence of papillary projections and cyst like space that presented the positivity of CD 31 and CD 68 antigen at immunochemical study. All this findings revealed the presence of a littoral cell angioma.

Analysis made on gastric lesion revealed a nodule of $8 \mathrm{~mm}$ with neoplastic proliferation, predominantly spindle cell, containing calcified areas, with negligible mitotic index ( $<1$ figure for HPF). The molecular and immunochemical study revealed the positivity for CD-117 +; CD-34 +; AML - markers, so they showed the presence of a low grade GIST. 


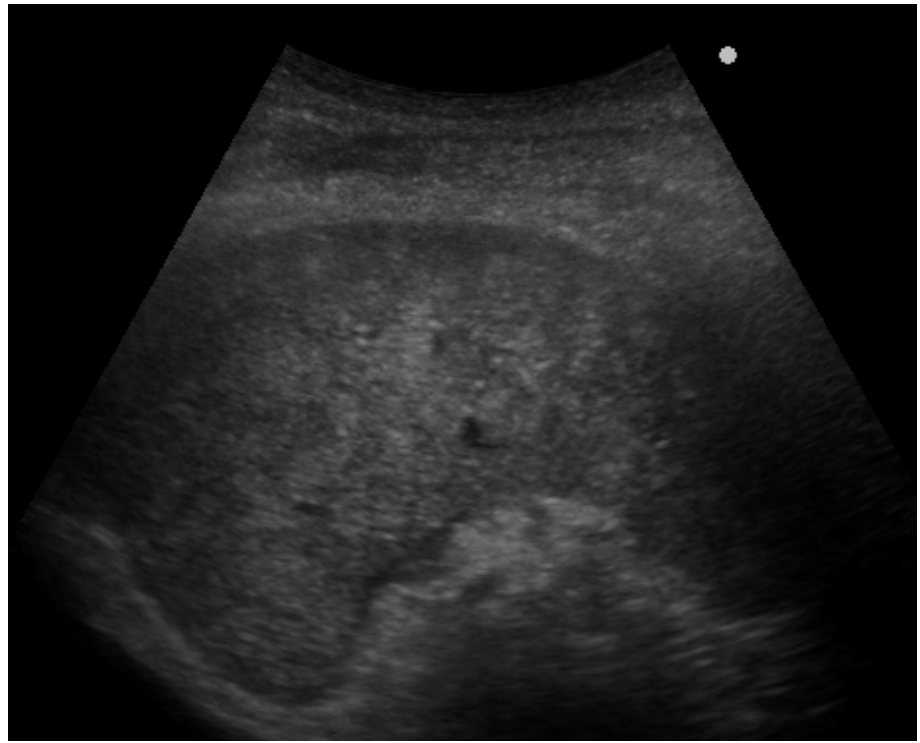

Figure 1: Image that shows the presence at US of multiple focal lesions of various shape and size

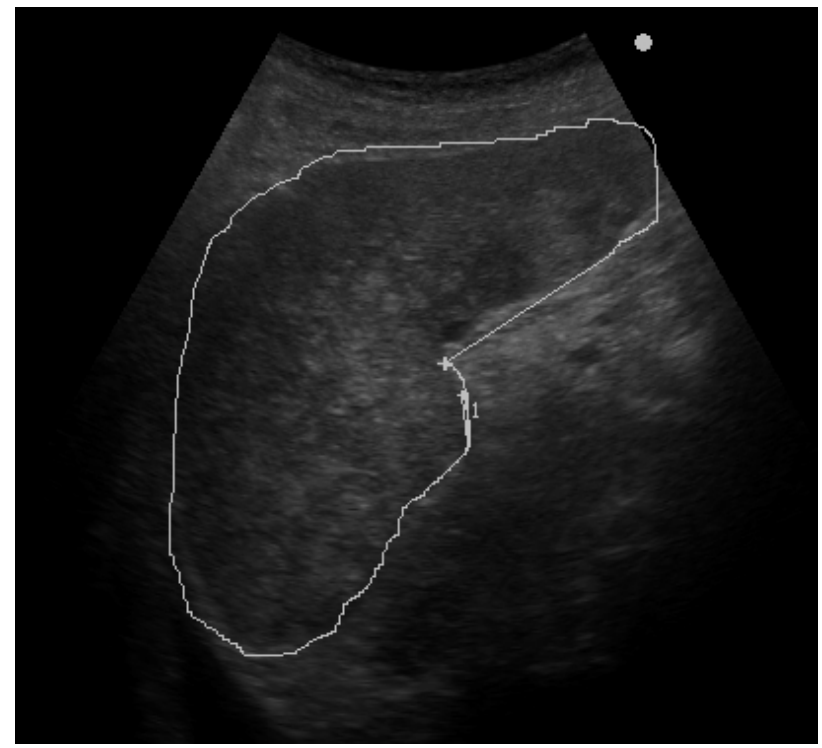

Figure 2: Image that indicates the presence of splenomegaly: area of $56 \mathrm{~cm}^{2}$

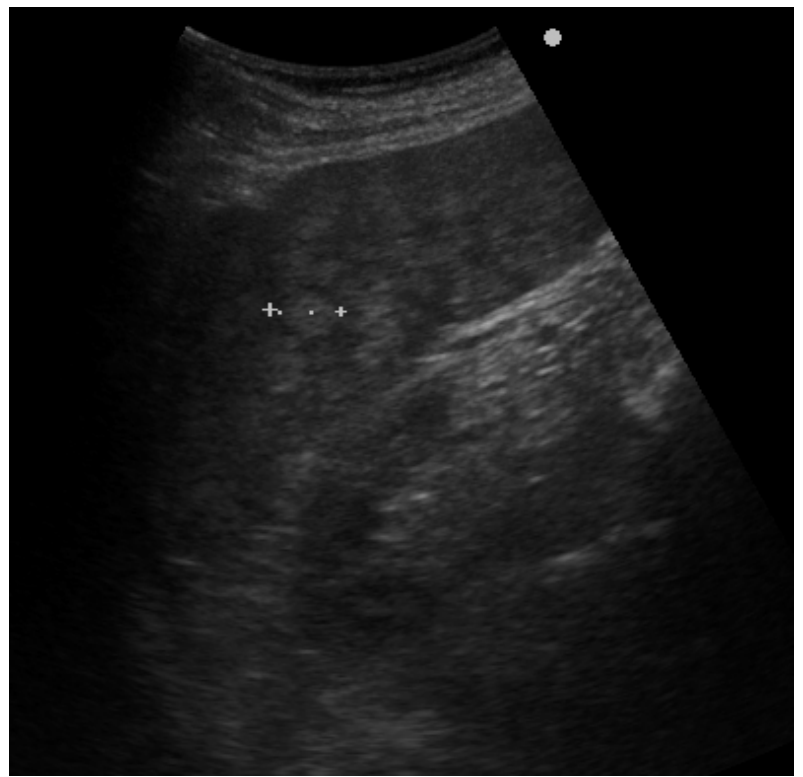

Figure 3: Different size of focal lesions 


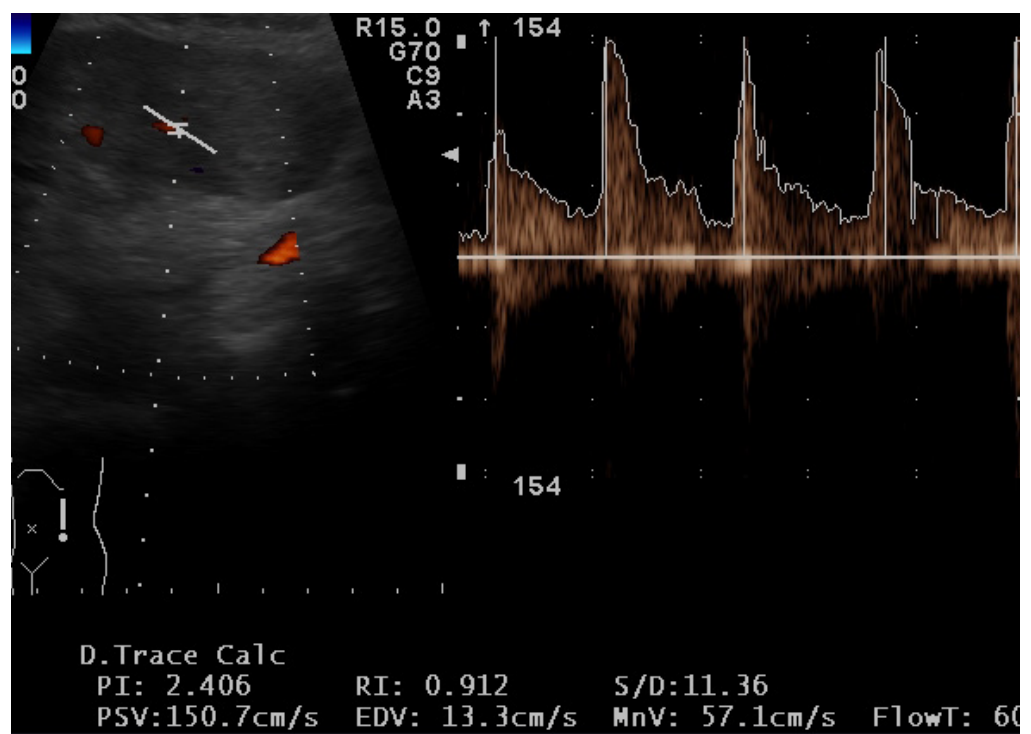

Figure 4: Splenic vascular resistive index

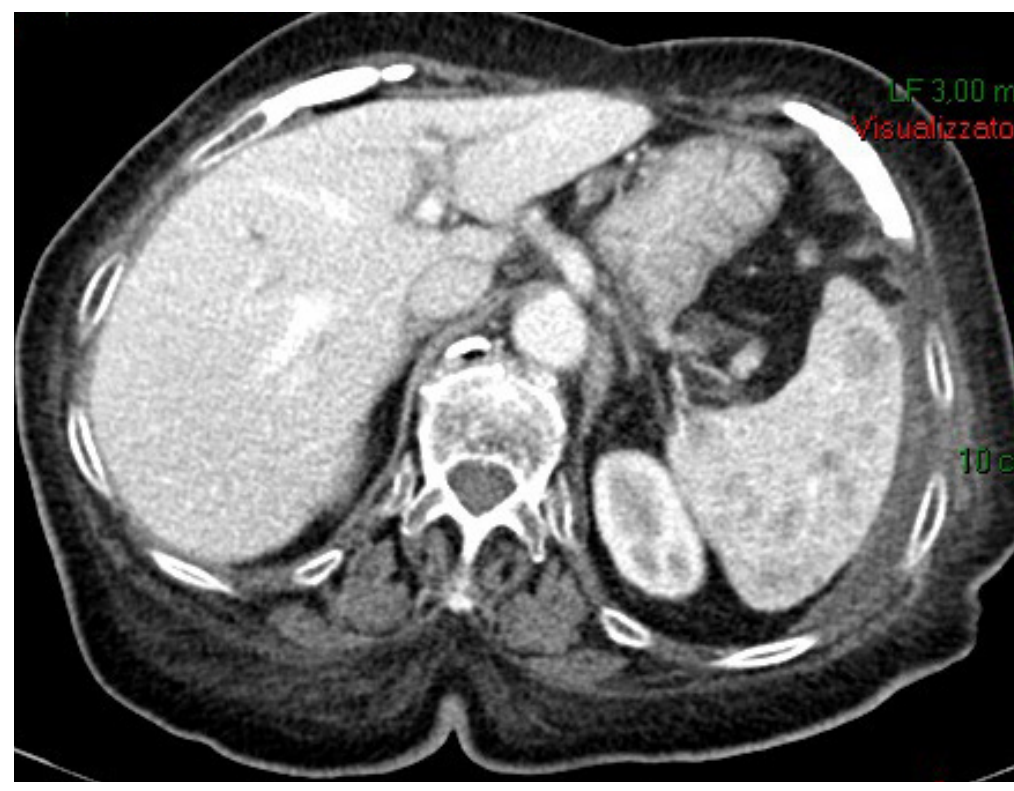

Figure 5: Hypodense lesions at CT study

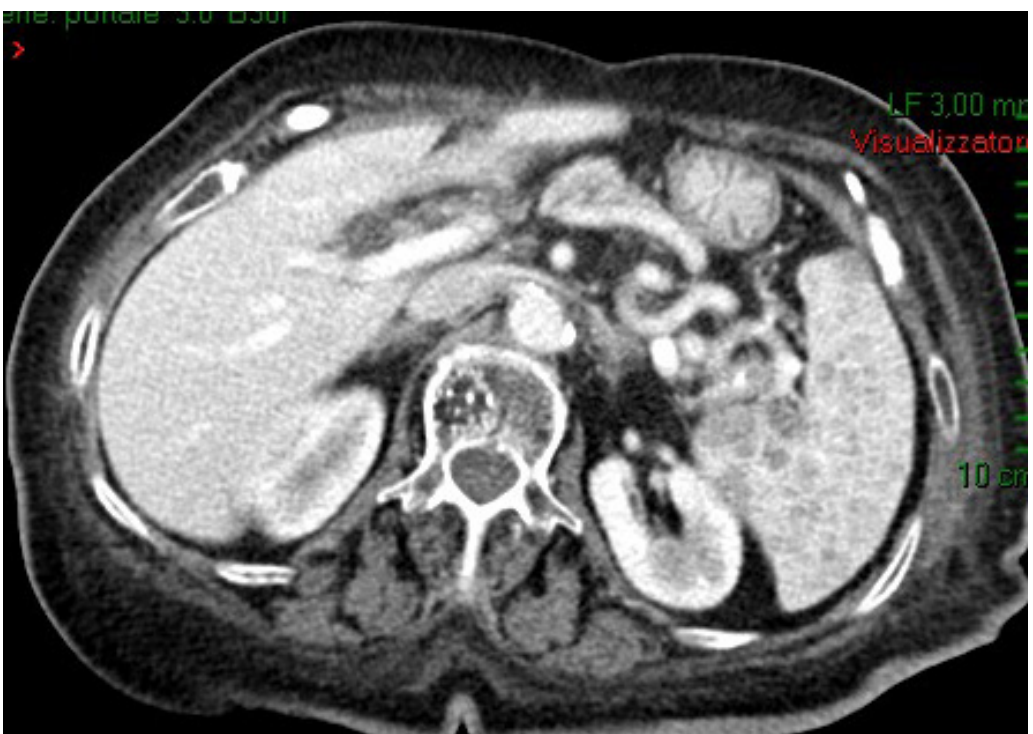

Figure 6: CT imaging of multiple splenic lesions in portal phase 
The hospitalization in surgery department was complicated by an episode of respiratory failure due to bronchial secretions that were removed with bronchoscopy and required antimicrobial and steroids therapy, with a progressive improvement. Now the patient is healthy and in follow-up by surgery physicians.

\section{Discussion}

Littoral cell angioma (LCA) is a rare vascular tumor that arises from the Littoral cells, that line the splenic red pulp [1]; first described in 1991 by Falk S et al. LCA is considered a benign vascular tumor with intermediate characteristics between endothelial cells and histiocytes; immunohistochemical markers are positive for the expression of CD31 (endothelial marker) and CD68 antingens (histiocitic marker) [2].

The clinical presentation of LCA may be heterogeneous: often LCA has no symptoms and is discovered incidentally during other imaging studies performed for other diseases. If it is symptomatic, patients may present with weakness, discomfort in the left upper quadrant of the abdomen, weight loss, fever of unknown origin, anemia and thrombocytopenia [3].

A possible association with various solid or hematologic tumors is described in the literature, as well as with dysregulation of the immune system [4], but a linkage is still unknown [5] because there are a small number of cases described in literature and so it is not well known whether this is a true association or can depend only on the highest number of tests required in the population with cancer [6].

Therefore it is appropriate to exclude malignancy in patients with incidental finding of LCA [7]. The sonographic features of LCA are also heterogeneous, because it can present with single lesion or multiple nodules that involve the entire splenic parenchyma; also it can be hypoechoic, hyperechoic or isoechoic.

In the 20 cases reported in English literature there was no prevalence of any specific ultrasound presentation; in fact they reported 10 cases of LCA in hyperechoic presentation and 10 cases with hypoechoic or isoechoic appearance [8].

Also the analysis of color Doppler signal is not characterizing. The sonographic appearance of LCA depends on the type and number of tumor vessels [8]. Even by CT scan, LCA is often indistinguishable from lymphomas, metastatic disease and hemangiomas [9].

\section{Conclusion}

Littoral cell angioma is a benign rare vascular tumor of the splenic red pulp, discovered incidentally during abdomen imaging study. Splenic alterations cannot be differentiated, at radiological evaluation, from other splenic pathologies as lymphomas, metastasis, amyloidosis, angioma; only histological and immunochemical evaluation can make the diagnosis. Splenectomy is the appropriate treatment, because LCA has the same presentation as splenic malignancy and it can develop, in rare cases, in a malignant form, despite its classification as benign tumor.

\section{References}

1. Ursuleac I, Iosif C, Bîrlă R, Dobrea C, Găman AM, et al. (2013) Littoral cell angioma of the spleen - a surprising cause of anemia. Rom J Morphol Embryol 54: 885-8.

2. Falk S, Stutte HJ, Frizzera G (1991) Littoral cell angioma. A novel splenic vascular lesion demonstrating histiocytic differentiation. Am J Surg Pathol 15: 1023-33.

3. Emir S, Sozen S, Yazar MF, Altınsoy HB, Arslan Solmaz O, et al. (2013) Littoral Cell Angioma of the Spleen. Arch Iran Med 16: 189-91.

4. Cordesmeyer S, Pützler M, Titze U, Paulus H, Hoffmann MW (2011) Littoral Cell Angioma of the Spleen in a patient with previous pulmonary sarcoidosis: a TNF-alfa related pathogenesis? World J Surg Oncol 9: 106.

5. O’Malley DP, Kim YS, Weiss LM (2015) Distinctive immunohistochemical staining in littoral cell angioma using ERG and WT-1. Ann Diagn Pathol 19: 143-5.

6. Leung VA, Tang S, Mahe E, Patlas MN (2012) Littoral Cell Angioma: Diagnosis by Image-Guided Biopsy. Ann Clin Lab Sci 42: 417-21.

7. Hu ZQ, A YJ, Sun QM, Li W, Li L (2011) The splenic Littoral Cell angioma in China: a case report and review. World J Surg Oncol 9: 168.

8. Zhang YH, Liu LM, Wang WP, Ding H, Wang XN, et al. (2013) Littoral cell angioma of the spleen: sonographic-pathologic comparison. J Ultrasound Med 32: 691-7.

9. Levy AD, Abbott RM, Abbondanzo SL (2004) Littoral Cell Angioma of the Spleen: CT Features with Clinicopathologic Comparison. Radiology 230: 485-90. 


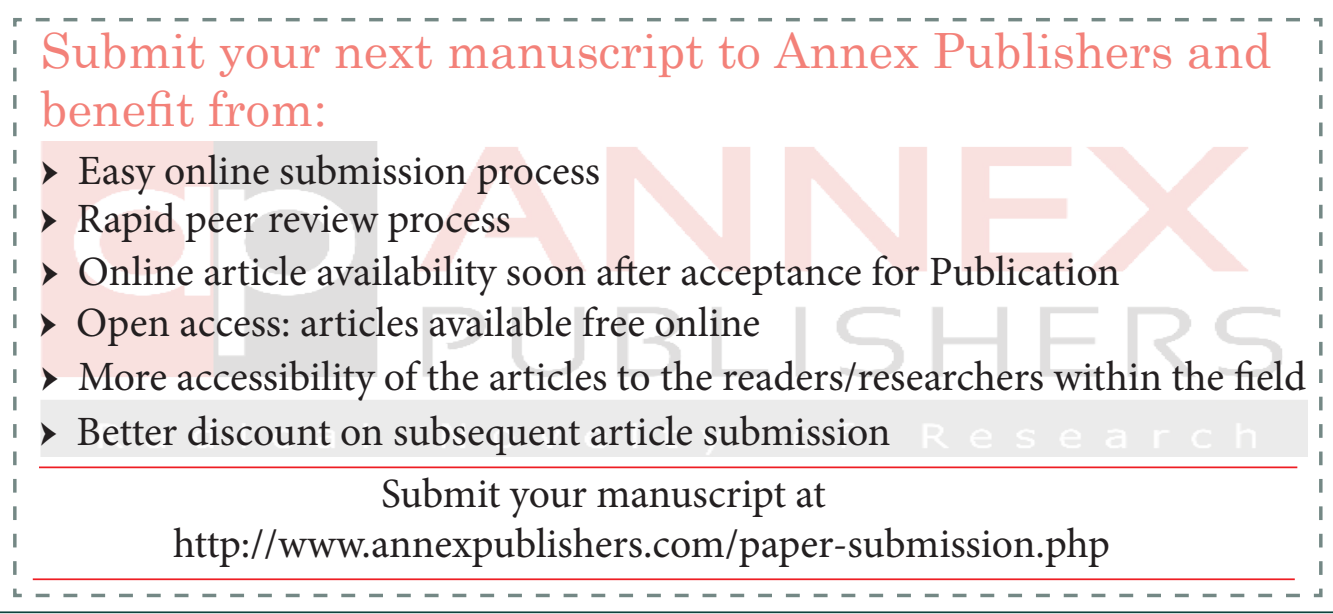

